\title{
Developing a spinal cord injury research strategy using a structured process of evidence review and stakeholder dialogue. Part III: outcomes
}

\author{
JW Middleton ${ }^{1}$, L Piccenna ${ }^{2}$, R Lindsay Gruen ${ }^{2,3,4}, \mathrm{~S}$ Williams ${ }^{5}$, G Creasey ${ }^{6}$, S Dunlop ${ }^{7}, \mathrm{D} \mathrm{Brown}^{8}$, \\ PE Batchelor ${ }^{9}$, DJ Berlowitz ${ }^{10}$, S Coates ${ }^{11}$, JA Dunn ${ }^{12}$, JB Furness ${ }^{13}$, MP Galea ${ }^{14}$, T Geraghty ${ }^{15}$, BK Kwon ${ }^{16}$, \\ $S$ Urquhart ${ }^{15}$, D Yates ${ }^{17}$ and $\mathrm{P}$ Bragge $^{2}$
}

Study design: Focus Group.

Objectives: To develop a unified, regional spinal cord injury (SCI) research strategy for Australia and New Zealand.

Setting: Australia.

Methods: A 1-day structured stakeholder dialogue was convened in 2013 in Melbourne, Australia, by the National Trauma Research Institute in collaboration with the SCI Network of Australia and New Zealand. Twenty-three experts participated, representing local and international research, clinical, consumer, advocacy, government policy and funding perspectives. Preparatory work synthesised evidence and articulated draft principles and options as a starting point for discussion.

Results: A regional SCl research strategy was proposed, whose objectives can be summarised under four themes. (1) Collaborative networks and strategic partnerships to increase efficiency, reduce duplication, build capacity and optimise research funding. (2) Research priority setting and coordination to manage competing studies. (3) Mechanisms for greater consumer engagement in research. (4) Resources and infrastructure to further develop SCl data registries, evaluate research translation and assess alignment of research strategy with stakeholder interests. These are consistent with contemporary international SCI research strategy development activities.

Conclusion: This first step in a regional $\mathrm{SCl}$ research strategy has articulated objectives for further development by the wider $\mathrm{SCl}$ research community. The initiative has also reinforced the importance of coordinated, collective action in optimising outcomes following SCl.

Spinal Cord (2015) 53, 729-737; doi:10.1038/sc.2015.87; published online 23 June 2015

\section{INTRODUCTION}

High-quality research that can positively impact clinical practice, outcomes and health policy can be facilitated through strategic prioritisation and planning. Spinal cord injury (SCI) is an area in which strategic research planning is of particular importance. Barrable ${ }^{1}$ recently articulated the need for an innovative, crossdisciplinary model to bridge the dual 'valleys of death' in research translation from 'bench to bedside', first from basic science into clinical research and development, and second the implementation of research evidence into clinical practice.

Targeting both 'cure' and 'care' are valid and important for ensuring that people with SCI benefit from research and biomedical advances that enhance neuroprotection and functional recovery, reduce the impact of secondary complications and underpin clinical best practice and policy to improve health, participation and quality of life. Promising advances in cellular, molecular and pharmaceutical therapies and technologies offer opportunities to restore function after injury or disease. However, many potential therapies have failed to translate to humans. ${ }^{2,3} \mathrm{~A}$ variety of reasons for this have been postulated, including difficulty in justifying and obtaining funding for follow-up or replication studies, ${ }^{3}$ lack of reporting standards, ${ }^{4}$ lack of reproducibility ${ }^{5}$ and premature acceleration of translation from laboratory to human studies because of pressure from consumer and other organisations. ${ }^{2}$ SCI 'care' research is also challenging because of

\footnotetext{
${ }^{1}$ John Walsh Centre for Rehabilitation Research, The University of Sydney, Sydney, New South Wales, Australia; ${ }^{2}$ National Trauma Research Institute, Monash University and The Alfred Hospital, Melbourne, Victoria, Australia; ${ }^{3}$ Monash University, Melboume, Victoria, Australia; ${ }^{4}$ Lee Kong Chian School of Medicine, Nanyang Technological University, Singapore; ${ }^{5}$ The Spinal Cord Injury Network, Sydney, New South Wales, Australia; ${ }^{6}$ Department of Neurosurgery, Stanford University School of Medicine, Stanford, CA, USA; ${ }^{7}$ Experimental and Regenerative Neuroscience, School of Animal Biology, The University of Western Australia, Perth, Western Australia, Australia; ${ }^{8}$ The Spinal Research Institute, Melbourne, Victoria, Australia; ${ }^{9}$ Department of Medicine (Austin Health), The University of Melbourne, Melbourne, Victoria, Australia; ${ }^{10}$ Institute for Breathing and Sleep, Austin Health, Melbourne, Victoria, Australia; ${ }^{11}$ State Rehabilitation Service, Fiona Stanley Hospital, Perth, Western Australia, Australia; ${ }^{12}$ Department of Orthopaedic Surgery and Musculoskeletal Medicine, University of Otago, Christchurch, New Zealand; ${ }^{13}$ Department of Anatomy and Neuroscience, The University of Melbourne, Melbourne, Victoria, Australia; ${ }^{14}$ Department of Medicine (Royal Melbourne Hospital), The University of Melbourne, Melbourne, Victoria, Australia; ${ }^{15}$ Queensland Spinal Cord Injuries Service, Princess Alexandra Hospital, Metro South Health, Brisbane, Queensland, Australia; ${ }^{16}$ Department of Orthopaedics, University of British Columbia, Vancouver, British Columbia, Canada and ${ }^{17}$ Rehabilitation Medicine, Canberra Hospital and Health Services, Garran, Australian Capital Territory, Australia

Correspondence: Professor JW Middleton, John Walsh Centre for Rehabilitation Research, The University of Sydney, Kolling Institute of Medical Research, Level 12, Royal North Shore Hospital, St Leonards, Sydney, New South Wales 2065, Australia.

E-mail: james.middleton@sydney.edu.au
}

Received 1 December 2014; revised 16 April 2015; accepted 17 April 2015; published online 23 June 2015 
the difficulty in adequate recruitment that can control for variations in mechanism, level and severity of injury in clinical trials ${ }^{6}$ combined with small SCI populations in single centres. ${ }^{2}$ Collaborative, multicentre research can increase available sample size, but is more complicated to conduct, for example, to ensure consistency between sites regarding patient selection, treatment and evaluation. ${ }^{2}$

The National Trauma Research Institute (NTRI), as part of the NTRI Forum programme, undertook a project in conjunction with the Australian and New Zealand Spinal Cord Injury Network (SCIN) to develop a regional SCI research strategy. Phase one of the Forum:

- Reviewed the volume, nature and findings of studies regarding priorities for SCI research. ${ }^{7}$

- Developed a briefing document that synthesised research evidence and expert one-on-one consultations to create a SCI research strategy 'roadmap,' framework, draft principles and options for deliberation. $^{8}$

This paper describes the outcomes of phase two of the Forum- a day-long structured stakeholder dialogue based upon the briefing document-and discusses these in the context of local and international developments.

\section{MATERIALS AND METHODS}

The stakeholder dialogue was held on 22 April 2013 in Melbourne, Australia. The broad aims of the NTRI Forum stakeholder dialogues are to:

- connect the information from the briefing document with the people who can make change happen; ${ }^{9}, 10$

- gather the views, experiences and tacit knowledge that these key stakeholders bring to the issues at hand; and

- motivate and inspire dialogue participants by bringing them together to address a common challenge. This use of collective problem solving can create outcomes that are not otherwise possible, because it transforms each individual's knowledge to a collective 'team knowledge' that can spark insights and generate action addressing the issue. ${ }^{11}$

The specific aims of this stakeholder dialogue were to bring clinicians, researchers, advocacy organisations, health system managers, policy makers and funding agencies together to:

1. Identify current key challenges in SCI research that a research strategy could address;

2. Determine the context of a regional research strategy, available resources and timelines;

3. Discuss key principles that could underpin a research strategy; and

4. Determine the next steps in developing a strategy.

Dialogue deliberations were professionally facilitated to respond to the issues presented in the briefing document, which included planning, methods, coordination, infrastructure, training and capacity building and funding. The dialogue allowed for frank, off-the-record deliberations by following the Chatham House rule: 'When a meeting, or part thereof, is held under the Chatham House Rule, participants are free to use the information received, but neither the identity nor the affiliation of the speaker(s), nor that of any other participant, may be revealed'. ${ }^{12}$ The dialogue did not aim for consensus, as participants in a dialogue cannot unilaterally commit their organisations to a course of action. ${ }^{13}$

We certify that all applicable institutional and governmental regulations concerning the ethical use of human volunteers were followed during the course of this research.

\section{RESULTS}

\section{Participants}

Twenty-three people participated in the stakeholder dialogue. Participants were identified and recruited using qualitative research principles; that is, purposefully sampled based on their specific knowledge or experience of the phenomenon of interest. ${ }^{8}$

Specifically, potential stakeholder dialogue participants were identified and invited if they represented a stakeholder group of relevance to the development of a SCI research strategy (that is, clinician, researcher, funder, service provider, advocate) at a senior/ leadership level. Of the participants, 11 were from Victoria, 11 were from other Australian States and Territories, and 3 were from outside of Australia, with one representative from New Zealand and the other two overseas participants being high-profile, internationally recognised leaders in the field bringing expertise in SCI research and advocacy. Collectively, the participants represented the following perspectives/ organisations (with some participants providing multiple perspectives):

- Research, including research leadership;

- Clinical practice, including clinical leadership;

- State Government Department of Human Services;

- Funding and service delivery organisations, including international funding organisations; and

- Consumer advocacy, research and networking organisations.

\section{Outputs}

A dialogue summary was prepared based upon notes taken by two NTRI Forum staff independently (audio of stakeholder dialogues is not recorded). These notes were qualitatively analysed by a senior researcher with qualitative research experience $(\mathrm{PB})$ to identify key themes and other information relevant to developing an Australian and New Zealand SCI Research Strategy. The primary output of the dialogue was a set of three overarching aims and three objectives of an Australian and New Zealand SCI Research Strategy. These are summarised in Table 1, which demonstrates how the draft principles developed and pre-circulated to dialogue participants ${ }^{8}$ were modified to create the objectives of the strategy. Each objective is then described in detail based upon dialogue deliberations and resulting qualitative thematic analysis.

\section{(1) Foster relevant high-quality research}

'Follow Good Research Practice' was originally framed as a principle within the 'methods' theme of the draft research strategy framework (Table 1). ${ }^{8}$ This principle was reframed as one of the three main objectives during dialogue deliberations, because it was felt to encompass many of the other principles articulated in the draft framework (see Table 1).

\section{(1a) Set priorities in a transparent and cooperative manner}

Alignment of research with prioritisation was recognised as critical to achieving the best outcome with resource limitations; however, managing competing interests by setting and implementing priorities was identified as a complex and potentially contentious task. Considerations that could inform decisions include the type of research, level of evidence, long- versus short-term outcomes and duration of research projects. An external body, such as a centralised clinical trials committee with broad SCI stakeholder representation, was proposed as a mechanism for prioritising, evaluating and 
Table 1 Summary of the aims and objectives of an Australian and New Zealand SCI Research Strategy in relation to precirculated draft principles $^{8}$

\section{OVERARCHING AIMS}

1. Optimise outcomes for people with SCI by increasing relevant high-quality research

2. Reduce the economic and social costs of SCl

3. Support the $\mathrm{SCl}$ research community to conduct high-quality research

\begin{tabular}{|c|c|c|}
\hline Strategy theme & Draft principle & $\begin{array}{l}\text { Objectives as adapted from draft principles during the } \\
\text { stakeholder dialogue }\end{array}$ \\
\hline 1: Planning & $\begin{array}{l}\mathrm{SCl} \text { research should address priority areas } \\
\mathrm{SCl} \text { research should minimise patient burden }\end{array}$ & $\begin{array}{l}\text { OBJECTIVE 1: Foster relevant high-quality research } \\
\text { 1a: Set priorities in a transparent and cooperative manner }\end{array}$ \\
\hline 2: Methods & $\begin{array}{l}\mathrm{SCl} \text { research should follow good practice } \\
\text { Innovation should be fostered, but findings should be tested in properly } \\
\text { conducted studies before translation into practice and policy }\end{array}$ & $\begin{array}{l}\text { 1b: Promote networking, communication, collaboration and } \\
\text { cross-disciplinary research } \\
\text { 1c: Enhance the evidence base for current clinical practice }\end{array}$ \\
\hline 3: Coordination & $\begin{array}{l}\mathrm{SCl} \text { research should be collaborative and aware of current national/international } \\
\text { research }\end{array}$ & $\begin{array}{l}\text { 1d: Foster innovation } \\
\text { 1e: Optimise involvement and participation of people with } \\
\mathrm{SCl} \\
\text { 1f: Follow good research practice }\end{array}$ \\
\hline 4: Infrastructure & $\begin{array}{l}\mathrm{SCl} \text { research should build capacity in infrastructure including data } \\
\text { sets/registries }\end{array}$ & $\begin{array}{l}\text { OBJECTIVE 2: Build capacity and infrastructure } \\
\text { 2a: Physical and human resources }\end{array}$ \\
\hline $\begin{array}{l}\text { 5: Training and capacity } \\
\text { building }\end{array}$ & $\mathrm{SCl}$ research should build capacity in research expertise & $\begin{array}{l}\text { 2b: Databases and registries } \\
\text { 2c: Adequate and continuing funding }\end{array}$ \\
\hline 6: Funding & $\mathrm{SCl}$ research should be financially realistic & $\begin{array}{l}\text { OBJECTIVE 3: Raise the profile of } \mathrm{SCI} \text { research } \\
\text { 3a: Demonstrate return on investment (for example, } \\
\text { reduced health-care costs) } \\
\text { 3b: Promote broader benefits of research } \\
\text { 3c: Ensure to meet interests of patients in terms of both } \\
\text { 'care' and 'cure' of SCl } \\
\text { 3d: Consider leadership and resources. }\end{array}$ \\
\hline
\end{tabular}

Abbreviation: SCl, spinal cord injury.

Table 2 Key features of a central committee for prioritising, evaluating and co-ordinating research

\begin{tabular}{ll}
\hline Feature & Rationale/reason \\
\hline Transparency & $\begin{array}{l}\text { This requires defined governance arrangements with accountable decision-making processes, supported by clear policies and } \\
\text { criteria for prioritisation and assessing feasibility }\end{array}$ \\
Stakeholder involvement & All relevant perspectives represented for equity and legitimacy reasons \\
Integration with wider research strategy & $\begin{array}{l}\text { Research planning and coordination should be consistent with the strategies of funding, consumer and other research } \\
\text { stakeholder organisations }\end{array}$ \\
Comprehensive database of research activity & An inclusive, up-to-date database of all current trial (and other) research activity is requisite
\end{tabular}

coordinating research. Key features pertaining to the operation of such a committee are summarised in Table 2.

Various trials committee models were discussed, including that of the Australian and New Zealand Intensive Care Society (ANZICS) Clinical Trials Group, ${ }^{14}$ formed through the experience of collaborating to conduct a large multicentre trial. However, important differences were highlighted between the SCI and intensive care research fields in terms of incident cases and number of participating researchers and units (for example, there are a total of 8 SCI units in Australia and New Zealand versus 73 current ANZICS member Intensive Care Units). The SCIN has a current Clinical Trials Committee. The terms of reference of the SCIN Clinical Trials Committee were discussed, noting the current focus on research quality. (1b) Promote networking, communication, collaboration and crossdisciplinary research. The importance of collaboration and the need to encourage more research involving multiple disciplines to address the complexities of SCI were emphasised. Formation of networks will build capacity by expanding pool of experienced clinical investigators, facilitate recruitment into large multisite studies and promote a more collaborative approach to funding. Poor awareness of research activity beyond local clinical settings can result in potential for duplication of effort. The Network for Excellence in Neuroscience Clinical Trials, or NeuroNEXT (http://www.neuronext.org/), was highlighted as an example of a network of multiple clinical sites with one Clinical Coordinating Centre and one Data Coordinating Centre. NeuroNEXT facilitates rapid protocol development to conduct phase II clinical trials of potential treatments for neurological disorders through partnerships with academia, private foundations and industry. 
Strategies identified to promote improved collaboration included: (1) harnessing existing organisations to pool research efforts locally, such as through SCIN and the Australian and New Zealand Spinal Cord Society (ANZSCoS), and internationally through The International Spinal Cord Society (ISCoS); (2) developing mechanisms that reward collaboration; and (3) encouraging a more collaborative approach to funding between state-based funding agencies. Communication must be enhanced at three levels: (1) between researchers to gather knowledge of planned trials that can inform research prioritisation and planning; (2) between the research community and people with SCI to promote better understanding of research priorities for people with SCI, as well as activities, findings and implications for translation; and (3) between preclinical and clinical researchers to aid priority setting and translation.

(1c) Enhance the evidence base for current clinical practice. This concept was originally encompassed under the draft research strategy framework principle that 'SCI research should be collaborative and aware of current national/international research', with collaboration already covered by $1 \mathrm{~b}$ above. In addition to creating new knowledge, the importance of translating evidence-based research into practice and policy was emphasised, and thought to be dependent upon awareness of published and current research. Resources to facilitate such awareness identified in the Forum process before the stakeholder dialogue included:

General trials databases:

- US National Institutes of Health ClinicalTrials.gov Registry: http:// clinicaltrials.gov

- Australian and New Zealand Clinical Trials Registry: http://www. anzctr.org.au/

- World Health Organization International Clinical Trials Registry Platform (ICTRP): http://www.who.int/ictrp/en/

SCI-specific trials databases:

- Spinal Cord Injury Network clinical trials database: http://www. spinalnetwork.org.au/research-and-clinical-trials/searchabledatabase
- European Multicenter Study About SCI (EMSCI) - ongoing trials: http://www.emsci.org/research/ongoing-clinical-trials

Published research repositories (SCI specific):

- SCIRE: http://www.scireproject.com/

- Evidence map: repository of SCI reviews: http://neurotrauma. evidencemap.org/

(1d) Foster innovation. Elements of the draft principle 'Innovation should be fostered, but findings should be tested in properly conducted studies prior to translation into practice and policy' that did not pertain to innovation were covered earlier under research prioritisation and planning (1a). The concept of innovation was only briefly discussed, but was felt to apply to any area of basic or clinical research, and therefore this aspect was retained as a stand-alone objective.

(1e) Optimise the involvement and participation of people with SCI. The concept of 'burden' referred to in draft principle was eliminated during discussion as it was felt that many people with SCI do not find participation in research burdensome and, in the context of informed consent, that research participation can bring benefits. Certain challenges to participant recruitment into SCI research were identified. From a much larger group of people living with SCI who are not currently involved in SCI research (estimated at over 9000 in Australia), trial data suggest that there is a group of $\sim 700$ 'serial enrollers' in SCI studies. While recognising that some people with SCI (such as those who are working, independent and satisfied with their life) may not have an interest in research, further research participants could be recruited (for example, through social networking). The importance of optimising the experience of being a participant in clinical SCI research was emphasised, with various strategies identified (see Table 3).

(1f) Follow good research practice. The importance of following good research practice was stressed along with the need to raise and maintain awareness among clinician researchers of its relevance to achieving high-quality research outcomes; for example, in relation to key issues such as randomisation and blinding. In particular, the

Table 3 Strategies for optimising the involvement and participation of people with $\mathrm{SCl}$ in clinical research

\begin{tabular}{|c|c|}
\hline Strategies & Rationale/reason \\
\hline $\begin{array}{l}\text { Understand priorities and incorporate perspectives of } \\
\text { people with } \mathrm{SCl}\end{array}$ & $\begin{array}{l}\text { Research questions and design should be informed by priorities/domains of importance to individuals with } \mathrm{SCl} \text {, } \\
\text { which may differ over time post injury (for example, views of a newly injured patient in acute care/rehabilitation } \\
\text { phase compared with a community-dwelling individual). Identification of meaningful outcomes allows person- } \\
\text { centred end points to be incorporated into the research process. }\end{array}$ \\
\hline Coordinate recruitment & $\begin{array}{l}\text { The way in which people with } \mathrm{SCl} \text { are approached to participate in research can be optimised through a single } \\
\text { point of contact/site coordinator using centralised data registries. This would reduce patient burden associated } \\
\text { with multiple approaches by researchers/teams or unnecessary inconvenience when participating in multiple } \\
\text { studies. }\end{array}$ \\
\hline Identify incentives & Consideration should be given to developing incentives to motivate research participation. \\
\hline $\begin{array}{l}\text { Provide accessible information and timely feedback to } \\
\text { research participants }\end{array}$ & $\begin{array}{l}\text { Potential research participants require easy access to essential information to enable them to choose between } \\
\text { possible projects. The provision of timely feedback to participants with } \mathrm{SCl} \text { regarding ongoing progress, findings } \\
\text { and implications of the research that they have been participating in will help to maintain interest and motivation } \\
\text { for future participation. }\end{array}$ \\
\hline Manage expectations of research participation & $\begin{array}{l}\text { Expectations of research participation (and the overall impact of the research) need to be managed. For example, } \\
\text { addressing a desire to 'not be in the control group' and also resolving differences between the expectations of } \\
\text { individuals with } \mathrm{SCl} \text { and those of clinicians. }\end{array}$ \\
\hline
\end{tabular}

Abbreviation: $\mathrm{SCl}$, spinal cord injury. 
pervasive issue of underpowered trials ${ }^{15}$ was highlighted as a major issue that must be addressed. It was acknowledged that existing standards (such as the CONSORT and PRISMA statements for reporting of trials and systematic reviews respectively) could be used to operationalise this principle. The difficulties associated with obtaining multisite ethics approvals in a timely way were noted to be another specific challenge that interferes with efficient and timely trial conduct.

\section{(2) Building capacity and infrastructure}

This objective encompassed the themes of infrastructure, training/ capacity building and funding from the draft research strategy framework (Table 1$){ }^{8}$

(2a) Physical and human resources. Developing and sustaining the necessary infrastructure for SCI research, including physical facilities, equipment and human resources, as well as a research culture, were seen as vital for good research practice. Current barriers were identified as: (1) inconsistency between research sites in terms of availability of specialised equipment, testing environments, offices, computers and library facilities; (2) insufficient human resources, including trial coordinators, research assistants and other support staff, exacerbated by staff turnover; and (3) lack of a research culture with a perception within SCI units and by some clinicians that they were 'being used' to facilitate research conducted by external researchers.

The importance of collaboration and utilisation of research networks was emphasised. Looking at how other cooperative networks have addressed infrastructure needs was suggested, along with the creation of 'core' facilities or centres of excellence as a way to build capacity around specific areas of research expertise. Overseas examples were described, including animal research and imaging centres of excellence. This concept could be broadened to include supporting key research trial functions (for example, research design and methodology, data collection, clinical trial coordinating centres-the National Health and Medical Research Council (NHMRC) Clinical Trials Centre being an example). Centres for animal proof-of-principle research might also be considered. The commitment and support of frontline clinical staff could be fostered by identifying incentives for therapists without a research background to become involved, such as looking at ways to harmonise 'little r' research (for example, research mandated through courses, college training, professional development points) with 'big R' research, such as multicentre trials. This could also minimise patient burden associated with involvement in multiple research projects. (2b) Databases and registries. Investing in registries that can be accessed by a large number of researchers and which possess a low volume of items and a low threshold for participation was identified as a strategy that has been successfully implemented in other settings where the patient population is small (for example, motor neurone disease). Embedding consumer participation in such registries could also optimise research participation. Minimum data sets for SCI have been established (ISCoS) that are now mandated for SCI research by certain funding agencies, such as the United States Department of Defense and National Institute of Neurological Disorders and Stroke. It was suggested that a peak body in Australia could do the same. Important challenges discussed in relation to the design and effective use of data registries are reported in Table 4.

(2c) Adequate and continuing funding. There is a lack of commercial imperative for SCI research and, currently, research is predominantly funded through insurers and other means. The challenge of developing a sustainable funding model accommodating both early career and established researchers in this context was identified, as was the importance of continuity of funding in order to facilitate long-term planning and coordination of research. New approaches to funding SCI research and partnering with industry were identified as an area of priority, as the long-term costs of trials are not sustainable for nongovernment organisations and other current research funders. Currently, momentum is lost at the conclusion of large funded programmes. Funding is predominantly state-based at present. It was suggested that seeking Federal or centralised funding could foster collaboration, although overseas experience has found that centralising funding does not necessarily result in collaboration on a national basis. Pursuing larger funding schemes, for example, in the area of chronic disease, was identified as a possible strategy that could be developed by ANZSCoS and ISCoS.

The role of funders in managing expectations of the extent and range of quality research that can be funded within a limited budget was identified. For example, only $20 \%$ of the NHMRC applications in Australia are funded on average, with approval rates slightly lower in the SCI sector. NHMRC advises particular sectors on funding strategies and to foster collaborations with specific organisations, for example via scholarships/fellowships. Particular funding schemes may be of strategic value. For example, partnership and fellowship grants may facilitate collaborations. Although funding is an obvious consideration for making a project feasible, this should be considered within a realistic financial context, with shrinking research budgets globally (for example, the US Department of Defense). Therefore, it

Table 4 Challenges to the design and use of data registries for research studies

\begin{tabular}{ll}
\hline Challenges & Rationale/reason \\
\hline Ensuring complete data capture & The coordinated efforts of advocacy organisations, researchers and clinicians will be necessary to achieve $100 \%$ of registrations \\
& for the prevalent $\mathrm{SCl}$ population. Gathering knowledge of exactly how many people in Australia and New Zealand are living with \\
Providing consent for ongoing data & The governance model and related issue of consent to facilitate tracking over time can be challenging.
\end{tabular}

collection

Checking research context

Data ownership and registry sustainability The issue of who owns data that accrue in a registry over time is important for planning. One model may be to facilitate ownership by the individuals with $\mathrm{SCl}$ of their own data. Utilising social networking could facilitate data capture and engage those not currently involved in SCl research.

Data privacy laws

Abbreviation: SCl, spinal cord injury.
Giving thought to what questions are going to be addressed and which data therefore should be captured provides a rationale to collect a minimum amount of information for registries. It can also help to address a poor understanding among the SCl community of the benefits of registry-based research.
Issues of privacy and security can interfere with data harmonisation and sharing. 
Table 5 Strategies identified to raise the profile of $\mathrm{SCl}$ research in Australia and New Zealand

\begin{tabular}{|c|c|}
\hline Strategies & Rationale/reason \\
\hline $\begin{array}{l}\text { Demonstrate return on investment and promote broader } \\
\text { benefits of research }\end{array}$ & $\begin{array}{l}\text { Showing how } \mathrm{SCI} \text { research can reduce the cost of care to the health system has proven a successful strategy } \\
\text { employed by an overseas } \mathrm{SCl} \text { funding organisation. Financial return on investment (ROI) was identified as an } \\
\text { important driver of research funding, although the need to consider and promote other benefits of research was } \\
\text { also acknowledged. Australia and New Zealand do not have large philanthropic research foundations. However, the } \\
\text { experience of international foundations is that public funding contributes substantially to SCI research and, } \\
\text { therefore, ROI and other data are essential to provide a rationale for research funding, reinforcing the importance } \\
\text { of maintaining good relationships between researchers and funding organisations. }\end{array}$ \\
\hline Support research targeting both 'cure' and 'care' & $\begin{array}{l}\text { Striking a balance between research that focusses on 'finding a cure' for } \mathrm{SCl} \text { (neuroprotection, repair and } \\
\text { regeneration) and research aiming to optimise and standardise care delivery and improve health, functioning, } \\
\text { participation and quality of life for people with } \mathrm{SCl} \text { was seen as important to decision-making. }\end{array}$ \\
\hline Assess proposals against key criteria & $\begin{array}{l}\text { Criteria such as feasibility, contribution to knowledge in the field and alignment with national health priority areas } \\
\text { used by the National Health and Medical Research Council require consideration in evaluating a research proposal. }\end{array}$ \\
\hline Identify resource requirements & $\begin{array}{l}\text { Thought needs to be given to the resources necessary to raise the profile of } \mathrm{SCl} \text { research in Australia and New } \\
\text { Zealand. }\end{array}$ \\
\hline Take broader contextual issues into account & $\begin{array}{l}\text { Issues such as health-care reforms, trends in treatment and rising costs globally were highlighted as relevant } \\
\text { considerations when advancing a SCl research strategy. For example, in Australia the development of a National } \\
\text { Disability Insurance Scheme is creating a new environment and conversations between 'care' stakeholders that } \\
\text { represents an opportunity to 'do something new together'. Identifying and focussing on strengths of our geographic } \\
\text { region was also considered important. }\end{array}$ \\
\hline
\end{tabular}

Abbreviation: $\mathrm{SCl}$, spinal cord injury.

was highlighted that care should be taken not to 'overshoot' with a research strategy.

\section{(3) Raising the profile of SCI research}

This third broad objective about a need to raise the profile of SCI research in Australia and New Zealand did not fit under any of the predetermined strategy themes or draft principles, but was considered integral to the strategy, providing a rationale to fund and support research (see $3 a-d$ in Table 1). Identified strategies for raising the profile of SCI research are provided in Table 5.

\section{DISCUSSION}

This is the first known initiative to develop a regional SCI research strategy in Australia and New Zealand and parallels recent international efforts. ${ }^{1}$ Key objectives of the Australia and New Zealand regional SCI research strategy can be summarised under four main themes: (1) 'collaboration', (2) 'coordination', (3) 'consumer engagement' and (4) 'resources'. These themes echo many of those identified through recent international activities for SCI research agenda setting and strategy development, ${ }^{1,16-18}$ demonstrating the strength of the Forum process. $^{8}$ This discussion reflects upon these themes in the context of these related initiatives.

\section{Collaboration}

Research networks can increase efficiency, reduce duplication of effort and build capacity. It is important to learn from and leverage the international community through existing networks, research consortia and funding initiatives. ${ }^{1,17-19}$ Effective translation is a two-way, iterative process with flow of ideas from bench to bedside to community and back. The process is critically dependent on close interactions between scientists, consumers and clinicians working as a team. ${ }^{18,20}$ This requires ways to facilitate communication and combine skills and disciplines in clinical and biological sciences through novel partnerships (for example, between public and private sectors). Collaborative research platforms such as the International Research Consortium laboratories (Christopher and Dana Reeve Foundation) and the Rick Hansen Spinal Cord Injury Registry (RHSCIR, Rick
Hansen Institute) bring together researchers and teams from different disciplines to accelerate translation of promising discoveries into tangible solutions.

Clinical networks of SCI centres with a coordinating centre-as exemplified by the EMSCI (http://www.emsci.org/), the North American Clinical Trials Network (NACTN: http://www.christopher reeve.org/site/c.ddJFKRNoFiG/b.8720879/k.B691/NACTN.htm) and the NeuroRecovery Network (http://www.christopherreeve.org/site/ c.ddJFKRNoFiG/b.5399929/k.6F37/NeuroRecovery_Network.htm)— can create the environment for multicentre trials, with development of highly trained personnel to undertake standardised assessments, collect data and coordinate clinical trials. Networks of funders can leverage limited resources into larger pools of money, providing efficiencies and avoiding duplication of effort.

Consumer networks can also bring together individuals and advocacy organisations around key issues affecting the lives of people with SCI, such as equipment, health care, information, employment, education and community service to better inform research design and best practice implementation. Examples include the European SCI Federation (http://www.escif.org/) and the newly formed Australian Spinal Injury Alliance, representing eight of Australia's state-based spinal cord injury organisations (https://scia.org.au/news/658-australian-spinal-injury-alliance).

\section{Coordination}

Research prioritisation is an inevitable consequence of centralised trial coordination. This can create tension between the rights of individual researchers to pursue their chosen lines of enquiry and the responsibility of the field as a whole to deliver the best possible research evidence to translate into SCI care and policy. Implementing centralised research prioritisation and coordination would represent a paradigm shift in regional SCI research planning. Nationally coordinated research processes require appropriate stakeholder engagement, ownership and representativeness, legitimacy, equity and transparency, accountability and sufficient resources. ANZICS provides a good model of how to facilitate investigator-initiated, collaborative clinical research throughout Australia and New Zealand. 
As one of the world's largest and most successful critical care research networks, incorporating 73 intensive care units and more than 600 clinicians and researchers, key ingredients for success of the network are good science, passion, leadership and organisation with transparent governance arrangements, as well as a willingness of researchers to put aside self-interest. Clear policies facilitate determination of relative network priorities for 'Competing Studies', as well as to encourage 'Co-enrolment' into clinical trials, where possible. ${ }^{14}$

Arguably, SCI research can be more multidisciplinary and complex with greater potential for competing interests than may be the case for research in an Intensive Care Unit setting. However, the example of ANZICS demonstrates that a defined framework and rationale reflecting an explicit vision and mission, such that decisions are based on clear value choices of the network, ${ }^{21}$ is critical to mitigating potential conflict and disenfranchisement arising from prioritisation processes. Health research prioritisation criteria include clinical importance, magnitude of the problem, likelihood of reducing burden, cost effectiveness, present knowledge, resources, ethical aspects, research capacity, novelty and controversy. ${ }^{22,23}$ Barrable $^{1}$ outlined 'relevancy' criteria used by the Rick Hansen Institute to establish SCI research priorities that include selecting the highest quality trials based on available science, impact of outcomes on people with SCI, stakeholder engagement in design and implementation, probability of long-term uptake, economic sustainability and opportunities to leverage funding support from other organisations.

In addition to numerous prioritisation criteria, there are various methods for evaluating selected criteria, including consensus-based and metrics-based approaches. ${ }^{22}$ Kwon et al.,24 highlighted the significant resourcing issues in SCI that are consequent to making the decision to translate experimental therapies into human clinical trials, not only in terms of the expense, time and workforce required, but the missed opportunity cost of evaluating another promising treatment. Their systematic approach to evaluating the strength of preclinical evidence and 'readiness' for translation involved agreed criteria for grading. These criteria included animal species, injury paradigms, time window and demonstration of clinically meaningful efficacy and reproducibility. ${ }^{5,24}$ The NACTN have further refined this approach. $^{25}$

\section{Consumer engagement}

For successful translation of research into health-care delivery and policy, it is imperative to have strong consumer engagement in research design and implementation. Such engagement not only assists with ensuring that priorities and domains of importance for individuals with SCI are understood, but also helps to validate individuals with SCI as genuine and credible stakeholders in the research process. ${ }^{26,27}$ This perspective can help unite different stakeholders. It can be achieved through focus groups, a consumer advisory committee (representative group of individuals with SCI and advocates) or broad engagement facilitated through advocacy organisations and the network alliances described earlier. Incorporating SCI consumer perspectives with the views of other SCI research stakeholders, such as researchers, clinicians, policymakers, funders and carers, is crucial to focus SCI research priorities.

There is also a clear role for individuals with SCI who are research literate to become more centrally involved in research development and implementation; for example, through graduate training and applied research experience by being an integral part of the research team, representation on clinical trial committees and SCI community liaison. To this end, a strategic alliance with two New Zealand universities has been established to create postgraduate study opportunities in the field of health sciences where the clinical practice components are replaced by the lived experience contribution. Despite limited direct evidence of impact in SCI, demonstration of active consumer involvement throughout the entire research process of design, participation, interpretation, dissemination and implementation is now being mandated by some funding agencies. The value that an expert consumer with SCI can bring to research is evident in protocols that are inclusive, address perceived barriers and provide incentives to enrolment. Individuals with the lived experience of SCI can convey a keen awareness and understanding of the day-to-day life with a SCI to research. Involving an array of SCI investigators in research design and development would ensure that research measures person-centred end points with meaningful outcomes that are important for people with SCI and their families. ${ }^{27,28}$

The stakeholder dialogue highlighted the need to increase the number of people with SCI who enrol as research participants. There is a relative lack of accurate and easily accessible information for consumers about research; for example, information about the purpose of the trial, eligibility criteria, time commitment and possible risks and benefits of participation. Centralised recruitment that harnesses registries and provides a single point of contact would likely increase capacity. The identification of residential location of people with SCI can also assist with determining realistic recruitment targets for different types of trials where substantial follow-up requirements may limit participation of those people residing outside metropolitan areas. Furthermore, efforts to facilitate more interaction and communication between individuals with SCI and researchers could help to reduce any perceived power and communication barriers. Creating a more accessible research environment for consumers may help to encourage a greater interest and a desire to engage in research projects by individuals with SCI. Finally, providing better feedback to participants of research results and their clinical implications is also essential for engagement and future participation in research trials.

\section{Resources}

Pivotal to the success of research networks are physical facilities, equipment and adequate human resources, such as trained research coordinators. Research coordinators can play a central role in recruitment and research coordination, access to databases, registries and other technologies. Researchers require high-quality data to generate and test hypotheses, and funding agencies rely on the same resources to accurately assess project feasibility. The Australian Spinal Cord Injury Register (ASCIR), a national population-based registry established in 1995, provides incident case registration and injury surveillance information from each of the six SCI units in Australia, but has very little capacity to facilitate or support clinical quality or research studies. An expanded and shared data platform with suitable arrangements for governance, privacy, security and accountability would facilitate data linkage across multiple Australian and New Zealand environments. This will facilitate collaborative multicentre research and enable evaluation of the effectiveness of research translation.

A research strategy should acknowledge and seek alignment with the interests of the target funders, although not necessarily be dictated solely by funding agencies (which by themselves may have their own strategies/interests). For example, where funding is driven by financial return on investment, translational research may be more likely to be funded. Yet for precommercial research and development of therapies, devices and diagnostics, longer time frames are required and different funding sources and novel structures need to be considered. ${ }^{1,18}$ Current funding mechanisms do not foster 'product' development 
from initial conception of the idea through finding or founding a start-up company, development and testing to ultimate regulatory approval and sales, with high regulatory hurdles, especially given the size of SCI population. ${ }^{17,18}$

Early involvement of industry in strategy and planning is important for several reasons. Industry is needed to fund very expensive clinical trials, sometimes costing tens of millions of dollars, but they need the input of researchers and clinicians to select realistic targets. High-profile failures of industry-sponsored trials can hurt the entire field, giving an impression that SCI management is not a commercially viable area. Similarly, researchers may sometimes embark on a research programme with little chance of commercial viability. One recent example was a first-in-human trial run by Geron to examine human embryonic stem cell transplants that was terminated. The experience has generated much discussion regarding ethical and social issues that should inform all stakeholders. ${ }^{29-31}$ Alignment of funder, researcher, clinician and consumer priorities is increasingly an international issue with multicentre and multinational dimensions.

\section{CONCLUSION}

Collaboration, coordination, consumer engagement and resources were identified as critical enablers for SCI research in Australia and New Zealand, given low incidence and prevalence of SCI, to avoid competition for funding and ensure feasibility to meet recruitment targets for adequately powered trials. All of these factors necessitate having a robust process for managing and balancing competing priorities and resolving differences in funding imperatives. The ANZICS model demonstrates that these challenges can be successfully managed in a sustainable model that increases research capacity and success for all.

This series of papers mark the beginning of a wider process of consultation and stakeholder engagement to gain input on the draft set of principles and next steps in strategy development, as well as to determine how this process could be lead. Efforts were made to involve several participants from New Zealand; however, only one was able to attend the dialogue. We hope to address this limitation through the subsequent efforts led by the Australian and New Zealand SCIN to implement key aspects of the research strategy.

With promising neuroprotective, reparative and restorative strategies emerging, increased pressure from consumers for early translation into human clinical trials and a greater focus on implementation of best practices, the need for committed, connected, cross-disciplinary networks of basic and applied researchers, clinicians and others has never been greater. Building capacity for clinical research (for example, clinical research coordinators) and infrastructure (for example, data registries) will be pivotal to realising the ambitions of a regional SCI research strategy. The ultimate aim of improving SCI care and outcomes will best be realised through a collective network approach that brings together all SCI research stakeholders who share this vision.

\section{DATA ARCHIVING}

There were no data to deposit.

\section{CONFLICT OF INTEREST}

Medical research funding organisations were represented in the dialogue from which this manuscript was developed. David Berlowitz received competitive research grants from the Transport Accident Commission (TAC) directly and from the Institute for Safety, Compensation and Recovery Research (ISCRR). His organisation (Institute for Breathing and Sleep) has also received such grants.

\section{ACKNOWLEDGEMENTS}

We thank the following: Professor Alan Mackay-Sim, Griffith University, Queensland, Australia; Peter Murray, Spinal Cord Injuries Australia; Peter Trethewey, AQA Victoria; Australia; Susan P Howley, Christopher \& Dana Reeve Foundation, USA; John A Bourke and Dr K Anne Sinnott Jerram, Burwood Academy of Independent Living and University of Otago, New Zealand. This project was funded by the Victorian Transport Accident Commission and the Spinal Cord Injury Network of Australia and New Zealand.

1 Barrable B. Model for bridging the translational 'valleys of death' in spinal cord injury research. J Healthc Leadersh 2014; 6: 15-27.

2 Tator $\mathrm{CH}$. Review of treatment trials in human spinal cord injury: issues, difficulties, and recommendations. Neurosurgery 2006; 59: 957-982.

3 Steward O, Popovich PG, Dietrich WD, Kleitman N. Replication and reproducibility in spinal cord injury research. Exp Neurol 2012; 233: 597-605.

4 Lemmon VP, Ferguson AR, Popovich PG, Xu XM, Snow DM, Igarashi M et al. Minimum information about a spinal cord injury experiment: a proposed reporting standard for spinal cord injury experiments. J Neurotrauma 2014; 31: 1354-1361.

5 Kwon BK, Soril LJ, Bacon M, Beattie MS, Blesch A, Bresnahan JC et al. Demonstrating efficacy in preclinical studies of cellular therapies for spinal cord injury - how much is enough? Exp Neurol 2013; 248: 299-300.

6 Dvorak MF, Noonan VK, Fallah N, Fisher CG, Rivers CS, Ahn H et al. Minimizing errors in acute traumatic spinal cord injury trials by acknowledging the heterogeneity of spinal cord anatomy and injury severity: an observational Canadian cohort analysis. J Neurotrauma 2014; 31: 1540-1547.

7 Bragge P, Piccenna L, Middleton J, Williams S, Creasey G, Dunlop S et al Developing a spinal cord injury research strategy using a structured process of evidence review and stakeholder dialogue. Part I: rapid review of $\mathrm{SCl}$ prioritisation literature. Spinal Cord 2015; 53: 714-720.

8 Bragge P, Piccenna L, Middleton J, Williams S, Creasey G, Dunlop S et al. Developing a spinal cord injury research strategy using a structured process of evidence review and stakeholder dialogue. Part II: background to a research strategy. Spinal Cord 2015; 53. 721-728

9 Lavis JN. How can we support the use of systematic reviews in policymaking? PLoS Med 2009; 6: e1000141.

10 Lavis JN, Posada FB, Haines A, Osei E. Use of research to inform public policymaking. Lancet 2004; 364: 1615-1621.

11 Cooke NJ, Salas E, Kiekel PA, Bell B.Advances in measuring team cognitionIn:Salas E, Fiore S(eds). Team Cognition: Understanding the Factors That Drive Process and Performance. American Psychological Association: Washington, DC: Washington, DC2004 pp 83-106.

12 Chatham House: The Royal Institute of International Affairs. Chatham House Rule 2014 (cited 10 November 2014). Available from http://www.chathamhouse.org/about/ chatham-house-rule.

13 Moat KA, Lavis JN, Clancy SJ, El-Jardali F, Pantoja TKnowledge Translation Platform Evaluation study team. Evidence briefs and deliberative dialogues: perceptions and intentions to act on what was learnt. Bull World Health Organ 2014 92: 20-28.

14 Australian and New Zealand Intensive Care Society. Clinical Trials Group 2014 Available from http://www.anzics.com.au/Pages/CTG/CTG-home.aspx.

15 Halpern SD, Karlawish JH, Berlin JA. The continuing unethical conduct of underpowered clinical trials. JAMA 2002; 288: 358-362.

16 Boninger ML, Brienza D, Charlifue S, Chen YY, Curley KC, Graves DE et al. State of the Science Conference in Spinal Cord Injury Rehabilitation 2011: introduction. Spinal Cord 2012; 50: 342-343.

17 Heinemann AW, Steeves JD, Boninger M, Groah S, Sherwood AM. State of the Science in Spinal Cord Injury Rehabilitation 2011: informing a new research agenda. Spinal Cord 2012; 50: 390-397.

18 Creasey G, McKenna S, Soril L, Samos C, Beekhuis G. A Roadmap for Spinal Cord Injury: The Stanford Symposium on Regeneration, Repair and Restoration of Function After Spinal Cord Injury 2012: Stanford School of Medicine.

19 Adams M, Carlstedt T, Cavanagh J, Lemon RN, McKernan R, Priestley JV et al. International spinal research trust research strategy. III: A discussion document. Spinal Cord 2007; 45: 2-14

20 Curt A. The translational dialogue in spinal cord injury research. Spinal Cord 2012; 50 352-357.

21 Sibbald SL, Singer PA, Upshur R, Martin DK. Priority setting: what constitutes success? A conceptual framework for successful priority setting. BMC Health Serv Res 2009 9. 43 .

22 Viergever RF, Olifson S, Ghaffar A, Terry RF. A checklist for health research priority setting: nine common themes of good practice. Health Res Policy Syst 2010; 8: 36.

23 Bragge P, Clavisi O, Turner T, Tavender E, Collie A, Gruen RL. The global evidence mapping initiative: scoping research in broad topic areas. BMC Med Res Methodol 2011; 11: 92

24 Kwon BK, Okon EB, Tsai E, Beattie MS, Bresnahan JC, Magnuson DK et al. A grading system to evaluate objectively the strength of pre-clinical data of acute neuroprotective therapies for clinical translation in spinal cord injury. J Neurotrauma 2011; 28: 1525-1543. 
25 Guest J, Harrop JS, Aarabi B, Grossman RG, Fawcett JW, Fehlings MG et al. Optimization of the decision-making process for the selection of therapeutics to undergo clinical testing for spinal cord injury in the North American Clinical Trials Network. J Neurosurg Spine 2012; 17: 94-101.

26 Simpson LA, Eng JJ, Hsieh JT, Wolfe DL. The health and life priorities of individuals with spinal cord injury: a systematic review. J Neurotrauma 2012; 29: 1548-1555.

27 Bourke J, Snell D, Sinnott K, Cassidy B. A user-led consultation model: making inclusion of service users in research a reality. Ethn Inequal Health Soc Care 2012; 5: 61-69.
28 Heinemann A. Developing quality metrics from patient-reported outcomes for medical rehabilitation: Patient-Centered Outcomes Research Institute, 2014 (cited 10 November 2014). Available from http://www.pcori.org/research-results/2013/ developing-quality-metrics-patient-reported-outcomes-medical-rehabilitation.

29 Chapman AR, Scala CC. Evaluating the first-in-human clinical trial of a human embryonic stem cell-based therapy. Kennedy Inst Ethics J 2012; 22: 243-261.

30 Eaton ML, Kwon BK, Scott CT. Money and morals: ending clinical trials for financial reasons. Current topics in behavioral neurosciences 2015; 19: 297-315.

31 Scott CT, Magnus D. Wrongful termination: lessons from the geron Clinical Trial. Stem Cells Transl Med 2014; 3: 1398-1401. 